\title{
Rancang Bangun Modul Praktikum Penggunaan Fotovoltaik
}

\author{
Andhika Wijayanto ${ }^{1}$, Khairuddin Karim ${ }^{2}$, Sunu Pradana ${ }^{3}$ \\ 1,2,3 Jurusan Teknik Elektro, Politeknik Negeri Samarinda \\ Jl. Dr. Ciptomangunkusumo, Kampus Gunung Lipan, Samarinda, 75131 \\ khairuddin_karim@polnes.ac.id
}

\begin{abstract}
Abstrak- Peralatan yang umum digunakan untuk pengujian kinerja sel fotovoltaik adalah simulator surya. Rancang bangun modul simulator surya ini berguna sebagai media pembelajaran. Simulator surya ini digunakan sebagai perangkat untuk menggantikan matahari sebagai sumber cahaya alami untuk penyinaran fotovoltaik dengan kondisi laboratorium. Pada perancangan ini dibangun sebuah sistem simulator surya berbasis lampu LED dengan pengendali Arduino. Dengan LED yang digunakan berjenis LED daya tinggi dengan beberapa jenis warna LED, memungkinkan intensitas yang dihasilkan lebih besar dibanding LED indikator dan untuk membandingkan pengaruh setiap spektrum warna terhadap daya keluaran dari fotovoltaik. Berdasarkan hasil pengujian modul simulator surya untuk penggunaan fotovoltaik ini, daya yang dihasilkan terhadap modul fotovoltaik 10 WP pada penyinaran maksimal LED yaitu tegangan rangkaian terbuka dapat mencapai $18 \mathrm{~V}$ dan arus hubung singkat adalah $42 \mathrm{~mA}$.
\end{abstract}

Kata kunci: Fotovoltaik, simulator surya, Arduino, LED, spektrum cahaya.

\section{Pendahuluan}

Sebagai negeri yang kaya, Indonesia sejatinya memiliki banyak potensi dalam memajukan kesejahteraan rakyatnya dengan memanfaatkan semaksimal mungkin sumber daya alam yang ada, terutama di bidang energi. Untuk itu diperlukan sumber daya manusia yang terampil, mampu mengelola kekayaan alam tersebut dengan mampu menggunakan teknologi serta ilmu pengetahuan yang terus berkembang.

Perkembangan teknologi dan ilmu pengetahuan sudah semakin pesat khususnya dalam bidang teknik elektronika dan teknik listrik, salah satu inovasi yang ada yaitu teknologi fotovoltaik yang merupakan suatu sektor teknologi yang berkaitan tentang pemanfaatan energi surya. Energi surya merupakan energi yang berupa sinar dan panas dari matahari. Setiap jam, matahari memberikan cukup energi ke bumi untuk memenuhi permintaan energi global selama setahun penuh [1]. Ini memberi gambaran umum tentang besarnya potensi energi matahari. Hal tersebut menuntut adanya ideide dalam pengembangan terhadap pemanfaatan energi matahari.

Hal ini yang mendasari penelitian-penelitian terhadap panel surya, tujuan penelitian itu sendiri adalah untuk menguji karakteristik dari sel fotovoltaik, mengevaluasi dan membandingkan dari berbagai jenis material fotovoltaik.
Simulator surya merupakan perangkat yang populer di industri fotovoltaik, digunakan sebagai pengujian sel fotovoltaik yang dilakukan pada kondisi di dalam ruangan yaitu pengujian laboratorium dengan merekayasa kondisi cahaya agar pengujian dapat sesuai dengan kondisi yang diinginkan. Penerapan teknologi LED untuk simulator surya sangat mungkin dilakukan mengingat telah banyak dilakukan penelitian dan percobaan untuk merencanakan dan membuat simulator surya berbasis LED dengan biaya produksi yang rendah.

Untuk mewujudkan sumber daya manusia yang mampu memanfaatkan teknologi fotovoltaik, maka perlu adanya perangkat sebagai teknologi pembelajaran khususnya kepada mahasiswa jurusan Teknik Elektro Politeknik Negeri Samarinda agar mampu memahami dan menggunakan perangkat fotovoltaik sebagai sarana pemanfaatan energi baru terbarukan di Indonesia. Dalam hal ini perangkat yang digunakan adalah modul surya dan simulator surya. Dengan dasar inilah minat untuk mengangkat judul "Rancang Bangun Modul Praktikum Penggunaan Fotovoltaik" dilakukan.

\section{LANDASAN TEOR}

\section{A. Energi Matahari}

Energi matahari adalah energi yang menopang kehidupan di alam semesta terutama di bumi sebagai tempat hidup untuk semua tanaman, hewan, dan manusia. Sumber energi matahari adalah interaksi nuklir pada inti Matahari, di mana energi berasal dari konversi hidrogen menjadi helium [1].

Sinar matahari sejauh ini merupakan sumber energi bebas karbon terbesar di planet ini. Lebih banyak energi dari sinar matahari menghantam bumi dalam 1 jam $\left(4,3 \times 10^{20} \mathrm{~J}\right)$ dari semua energi yang digunakan di planet ini dalam setahun $\left(4,1 \times 10^{20} \mathrm{~J}\right)[1]$. Hal tersebut membuktikan bahwa bumi menerima energi matahari berkali lipat lebih banyak dibandingkan energi yang telah dikonsumsi dari sumber lain seperti bahan bakar fosil [2].

\section{B. Spektrum Matahari}

Setiap benda tak terkecuali matahari memancarkan energi pancaran dengan jumlah yang merupakan fungsi dari suhunya. Energi matahari bertransmisi ke Bumi melalui gelombang elektromagnetik yang menghasilkan radiasi termal. Benda hitam (black body) merupakan istilah untuk benda yang mampu menyerap radiasi elektromagnetik 
dengan baik, tidak ada yang dapat keluar atau dipantulkan, namun secara teori benda hitam juga harus memancarkan seluruh panjang gelombang energi tersebut agar dapat diukur. Jumlah energi yang dipancarkan bergantung pada suhu dari benda hitam tersebut, semakin tinggi suhu dari benda hitam tersebut maka semakin besar energi yang dipancarkan [2].

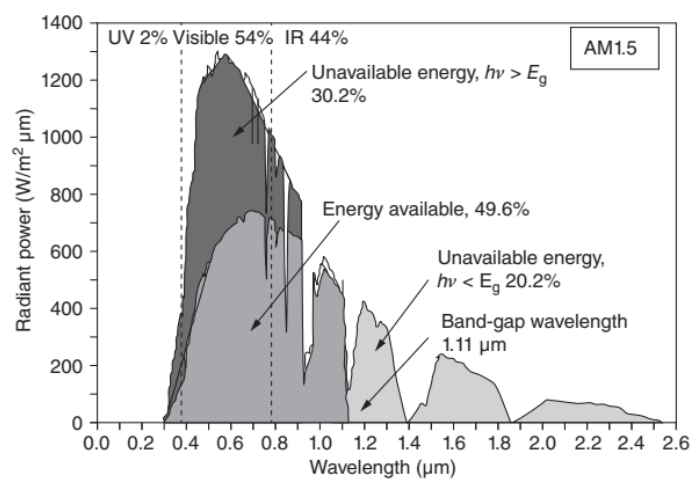

Gambar 1. Energi pada spektrum matahari AM 1.5[2]

Spektrum elektromagnetik pada dasarnya membawa jumlah foton atau energi yang berbeda di panjang gelombang tertentu, begitu pula untuk spektrum matahari pada AM 1.5 menunjukkan dampak energi yang tidak dapat digunakan oleh sel PV silikon kristal ditunjukkan pada Gambar 1, di mana foton (hv) dan celah pita silikon (Eg) harus seimbang sesuai dengan kemampuan sel fotovoltaik. Foton dengan panjang gelombang lebih dari $1.11 \mu \mathrm{m}$ tidak memiliki energi yang cukup untuk mengeluarkan elektron (20,2\% dari energi matahari yang masuk); pada rentang panjang gelombang yang lebih pendek tidak dapat menggunakan semua energinya, yang menyumbang 30,2\% tidak adanya energi [2].

Terdapat $20,2 \%$ dari energi dalam spektrum hilang karena foton memiliki energi lebih sedikit daripada celah pita silikon (hv <Eg) dan 30,2\% lainnya hilang karena foton dengan $h v>$ Eg. Sedangkan 49,6\% sisanya mewakili fraksi maksimum yang mungkin dapat dikumpulkan dari energi matahari oleh sel surya silikon [2].

\section{Sel Surya}

Sel surya merupakan alat atau perangkat yang umumnya terbuat dari bahan semikonduktor untuk mengubah energi sinar matahari menjadi energi listrik, semikonduktor yang sama digunakan pada komponen elektronika saat ini.

Sel surya memiliki 2 bagian yang disebut $P$-type layer dan $N$-type layer, sel surya dibuat dengan 2 material berbeda untuk mencegah adanya rekombinasi, yaitu ketika sel surya terpapar foton dengan energi di atas energi celah pita, pasangan lubang-elektron akan dibuat kemudian elektronelektron itu dapat jatuh kembali ke dalam lubang yang menyebabkan kedua pembawa muatan menghilang.

Untuk membuat medan listrik, dua daerah didirikan di dalam kristal. yang terjadi di sekitar persimpangan p-n saat terkena sinar matahari. Saat foton diserap, pasangan lubangelektron dapat dibentuk. Jika pasangan lubang-elektron ini mencapai sekitar persimpangan, medan listrik di daerah deplesi akan mendorong lubang ke sisi p dan elektron ke sisi-n seperti yang ditunjukkan pada Gambar 2. Sisi-p

Submitted: 25/10/2020; Revised: 25/10/2020;

Accepted: 05/11/2020; Online first: 31/12/2020

http://dx.doi.org/10.46964/poligrid.v1i2.534 mengakumulasi lubang dan sisi-n mengakumulasi elektron, yang menciptakan tegangan yang dapat digunakan untuk mengalirkan arus ke beban [2], [3].

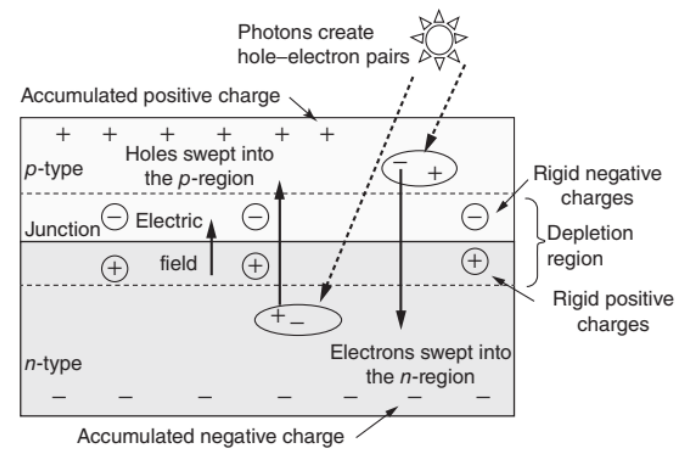

Gambar 2. Reaksi atom pada sel surya terhadap foton[2]

Gambar 3 menunjukkan apabila sel dihubungkan dengan beban $\mathrm{R}$, maka akan memberi hambatan sebagai garis linear dengan garis $I / V=I / R$, hal tersebut menunjukkan daya yang didapat bergantung pada daerah kurva MN, di mana sel beroperasi sebagai sumber arus $\left(I_{s c}\right)$. Pada sisi lain jika $R$ besar, sel beroperasi pada daerah kurva PS, di mana sel beroperasi sebagai sumber tegangan $\left(\mathrm{V}_{\mathrm{oc}}\right)$. jika dihubungkan dengan hambatan optimal $\left(R_{\text {opt }}\right)$ berarti sel surya menghasilkan daya maksimal dengan tegangan maksimal dan arus maksimal [4].

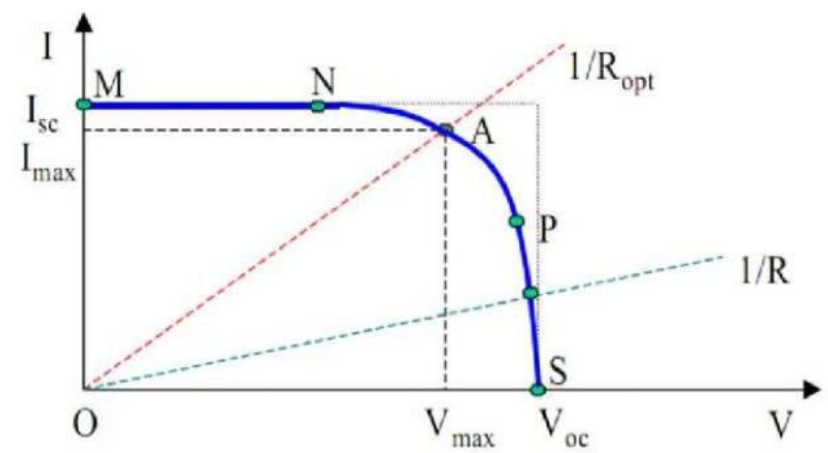

Gambar 3. Karakteristik I-V fotovoltaik

\section{Simulator Surya}

Simulator surya adalah perangkat sebagai pengganti matahari sampai batas tertentu, pada simulator surya komersial umumnya dapat menawarkan intensitas dan komposisi spektral menyerupai sinar matahari alami. Hal ini banyak digunakan sebagai fasilitas pengujian dalam ruangan yang dapat dikendalikan yaitu kondisi laboratorium untuk sel surya, tabir surya, plastik dan bahan lain yang sensitif terhadap sinar matahari.

Untuk meningkatkan serangkaian kondisi pengujian yang standar untuk sel PV aplikasi terestrial, dua lokakarya, disponsori oleh ERDA dan NASA, berlangsung pada tahun 1975 dan 1977 dan laporan akhir dari prosedur pengukuran fotovoltaik terestrial standar, termasuk deskripsi terperinci dari simulator surya standar, diterbitkan setelah lokakarya kedua. Dalam laporan tersebut, $1000 \mathrm{~W} / \mathrm{m}^{2}$ dipilih sebagai intensitas standar sementara massa udara, AM1.5 dipilih 
sebagai komposisi spektral, dan keduanya masih digunakan dalam standar ASTM untuk simulator surya komersial. Selain itu, $1000 \mathrm{~W} / \mathrm{m}^{2}$ biasanya dipilih sebagai unit radiasi matahari $\left(1\right.$ matahari $\left.=1000 \mathrm{~W} / \mathrm{m}^{2}\right)$ yang banyak digunakan dalam penelitian tata surya terkonsentrasi [5].

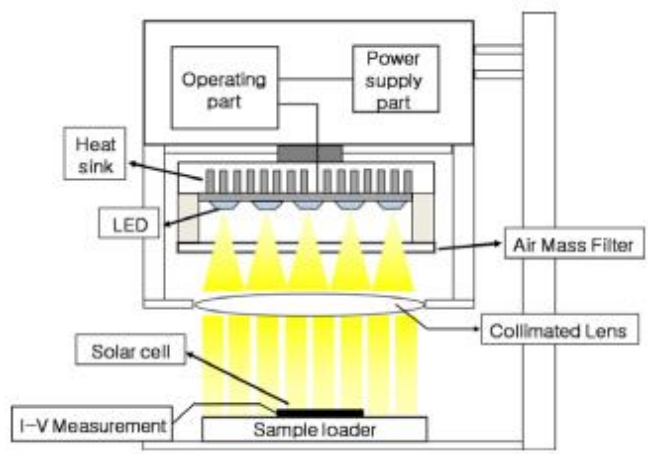

Gambar 4. Skematik simulator surya berbasis LED[5]

\section{E. Teknologi Light Emmiting Diode (LED)}

LED adalah perangkat semikonduktor yang dapat memancarkan cahaya pada Panjang gelombang (warna) tertentu. Area aktif LED atau disebut die terbungkus plastik atau rumah keramik yang dapat menggabungkan satu atau lebih die. Ketika LED diberi arus pada bias maju (dihidupkan), elektron dapat bergabung kembali dengan lubang di dalam perangkat dan melepaskan energi dalam bentuk foton disebut electroluminescence [6].

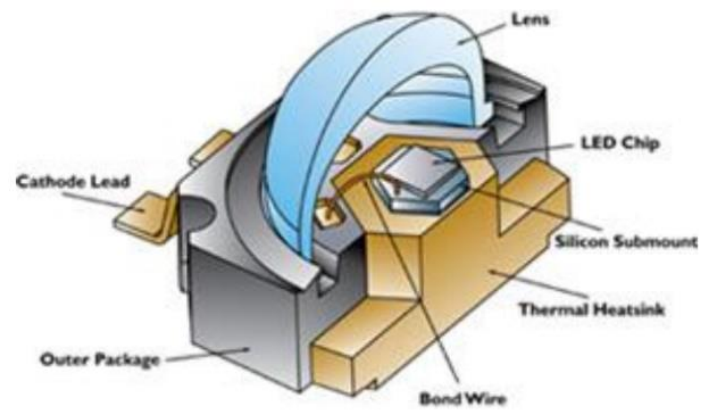

Gambar 5. Skematik konstruksi LED iluminator[7]

LED serupa dengan diode normal yang terdiri dari chip bahan semikonduktor yang diolah dengan pengotoran untuk membuat $\mathrm{p}-\mathrm{n}$ junction, atom pada material tipe-n memiliki lebih banyak elektron. Sedangkan atom pada material sisi-p memiliki lubang elektron, apabila diterapkan sumber tegangan membuat arus yang mengalir mendorong atom ke arah junction, membuat atom tipe-n mentransferkan elektron mereka yang berlebih ke atom tipe-p dan menerimanya. Muatan negatif pada sisi $\mathrm{n}$ membuat arus mengalir dari area muatan (-) ke area dengan muatan (+) yang disebut forward bias [7].

LED karena bekerja pada daya yang tinggi atau high brightness LED, memiliki arsitektur dasar yang sama dengan LED pada umumnya seperti yang ditunjukkan pada Gambar 5, pada LED tipe ini juga memiliki komponen tambahan yaitu heat sink aluminium yang umumnya sudah terpasang menjadi satu bagian dengan LED karena jenis
LED ini akan menghasilkan panas yang lebih dibanding tipe indicator [7].

\section{F. Arduino Board}

Arduino adalah single board microcontroller yang bersifat opensource yang di dalamnya terdapat komponen utama yaitu sebuah IC mikrokontroler dengan jenis AVR dari perusahaan Atmel. Mikrokontroller sendiri merupakan IC (Integrated Circuit) yang bisa diprogram menggunakan komputer melalui software IDE [8]. Tujuan ditanamkannya program pada mikrokontroler adalah agar rangkaian elektronik dapat membaca input, memproses input tersebut kemudian menghasilkan output sesuai yang diinginkan. Jadi mikrokontroler bertugas sebagai "otak" dari sebuah rangkaian elektronik. Berbagai papan Arduino menggunakan tipe ATmega yang berbeda-beda tergantung dari spesifikasinya, sebagai contoh Arduino UNO menggunakan ATmega328 sedangkan Arduino Mega 2560 yang lebih canggih menggunakan ATmega 2560 [8].

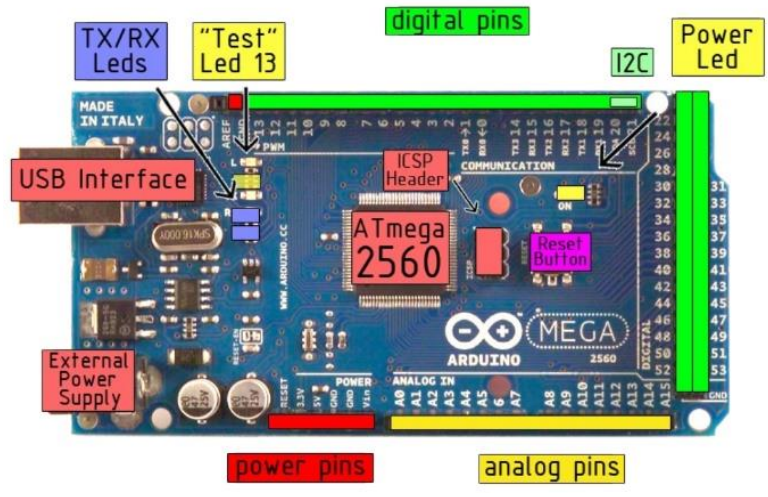

Gambar 6. Skematik pin pada Arduino Mega2560[9]

\section{Metodologi PeRANCANGAN}

\section{A. Gambaran Umum Sistem}

Simulator surya yang dirancang dan dibangun ini merupakan modul untuk mensimulasikan matahari sebagai alat yang digunakan untuk mempraktikkan penggunaan fotovoltaik di dalam ruangan. Dengan sistem operasi secara terprogram menggunakan mikrokontroler berbasis Arduino Mega2560. Berikut diagram blok sistem yang ditunjukkan pada Gambar 7 merupakan proses kerja dari alat tersebut.

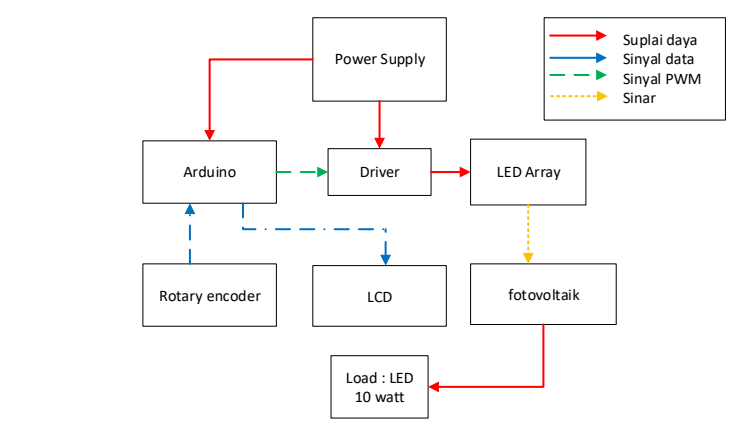

Gambar 7. Diagram blok sistem 


\section{B. Perancangan Wadah Sistem}
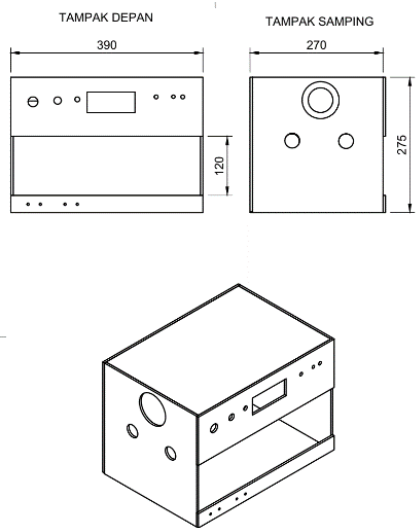

Gambar 8. Desain Bentuk dan dimensi wadah untuk sistem

Pada perancangan wadah untuk alat ini digunakan aplikasi Autodesk Fusion 360, merupakan aplikasi desain grafis CAD 3D, dengan perancangan wadah ditunjukkan pada Gambar 8. Terdapat beberapa lubang yang dibuat pada bagian depan atas sebagai tempat beberapa komponen kontrol dan LCD, pada sisi kiri dan kanan terdapat masingmasing 3 lubang untuk kipas.

\section{Perancangan Sistem LED Array}

Pada tahapan ini dilakukan pengerjaaan desain sketsa dari susunan LED menggunakan aplikasi Autodesk Fusion 360 dan berikut desain yang telah dibuat sebagai acuan dalam penyusunan LED, sketsa ditunjukkan pada Gambar 9.

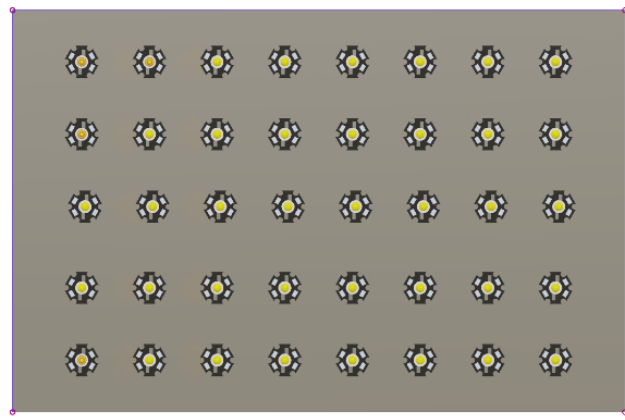

Gambar 9. Sketsa susunan LED

Untuk posisi pemasangan macam-macam warna LED ditunjukkan pada Gambar 10. dengan dominan yang digunakan adalah warna putih sebanyak 24 buah, kemudian terdapat warna seperti hijau, biru, merah dan putih hangat yang masing-masing berjumlah 4 buah.

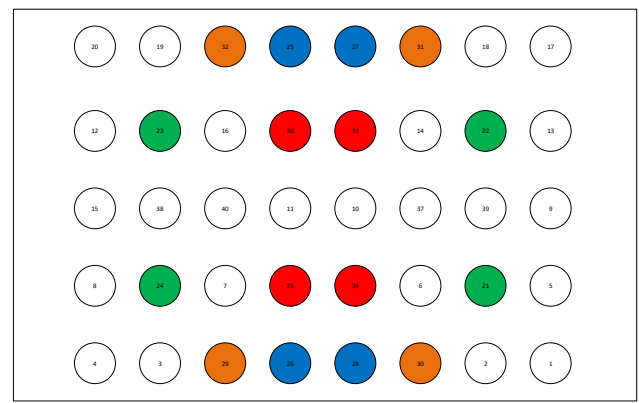

Gambar 10. Tata Letak setiap warna LED

Submitted: 25/10/2020; Revised: 25/10/2020;

Accepted: 05/11/2020; Online first: 31/12/2020

http://dx.doi.org/10.46964/poligrid.v1i2.534

\section{Perancangan Sistem LED Driver}

Dalam perancangan sistem $L E D$ driver, digunakan aplikasi untuk melakukan simulasi dan pembuatan rancangan rangkaian., yaitu aplikasi Fritzing dan LT Spice XVII. Seperti yang ditunjukkan pada Gambar 11, merupakan rangkaian setiap MOSFET yang terhubung pada arduino sebagai pengendali dan terhubung pada empat LED sebagai beban.

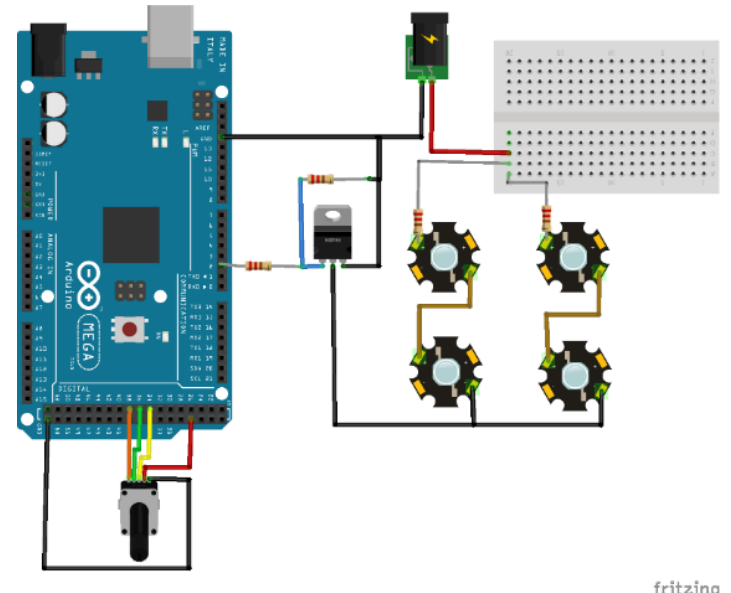

Gambar 11. Skematik rangkaian pada 1 MOSFET untuk beban 4 LED

LED yang digunakan adalah jenis high power LED dengan spesifikasi sebagai berikut:

TABEL 1

SPESIFIKASI LED $\llbracket 10]$

\begin{tabular}{|l|l|}
\hline Parameter & Rating \\
\hline Power $(P)$ & 1 Watt \\
\hline Forward current $(I F)$ & 0.35 Ampere \\
\hline Forward voltage $(V F)$ & 3.4 Volt \\
\hline Operating temperature range & $-20^{\circ} \mathrm{C}$ to $+80^{\circ} \mathrm{C}$ \\
\hline
\end{tabular}

Gambar 12 menunjukkan rangkaian daya untuk seluruh susunan LED simulator surya.

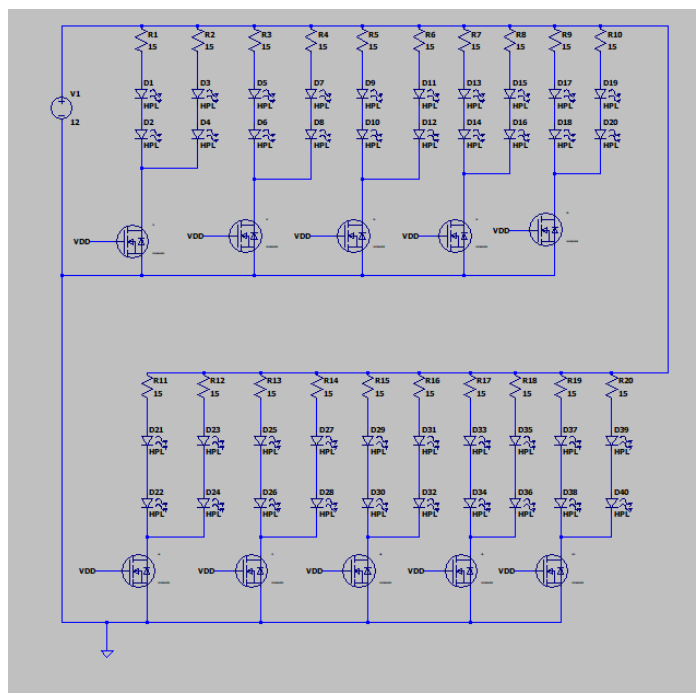

Gambar 12. Rangkaian daya seluruh LED 
PCB yang digunakan sebagai rangkaian sistem terdapat dua bagian yaitu untuk rangkaian resistor LED dan rangkaian MOSFET. Untuk PCB pada rangkaian resistor memiliki ukuran dengan panjang $=38 \mathrm{~cm}$ dan lebar $=26 \mathrm{~cm}$, ukuran tersebut untuk menyesuaikan letak dari LED, dengan tujuan mengurangi penggunaan kabel penghantar. Skematik PCB ditunjukkan pada Gambar 13.

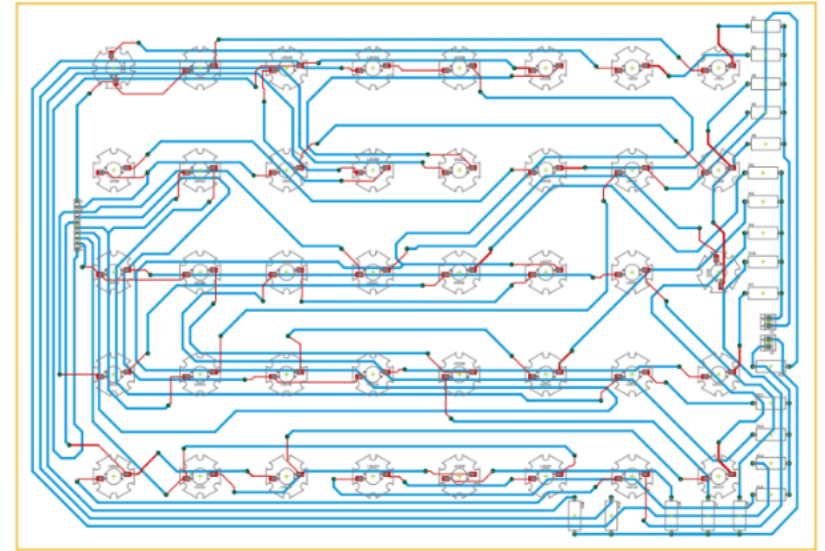

Gambar 13. Desain PCB untuk susunan LED

Desain PCB untuk MOSFET ditunjukkan pada Gambar 14, pada PCB ini terdiri dari 10 buah MOSFET, 20 resistor dan $20+1$ pin header. Untuk resistor terdiri dari 10 buah resistor gate dengan nilai $\mathrm{R}=10 \Omega$ dan 10 resistor gate-source $\mathrm{R}=1 \mathrm{~K} \Omega$. Dengan dimensi $\mathrm{PCB}$ adalah panjang $=19 \mathrm{~cm}$ dan lebar $=14 \mathrm{~cm}$.

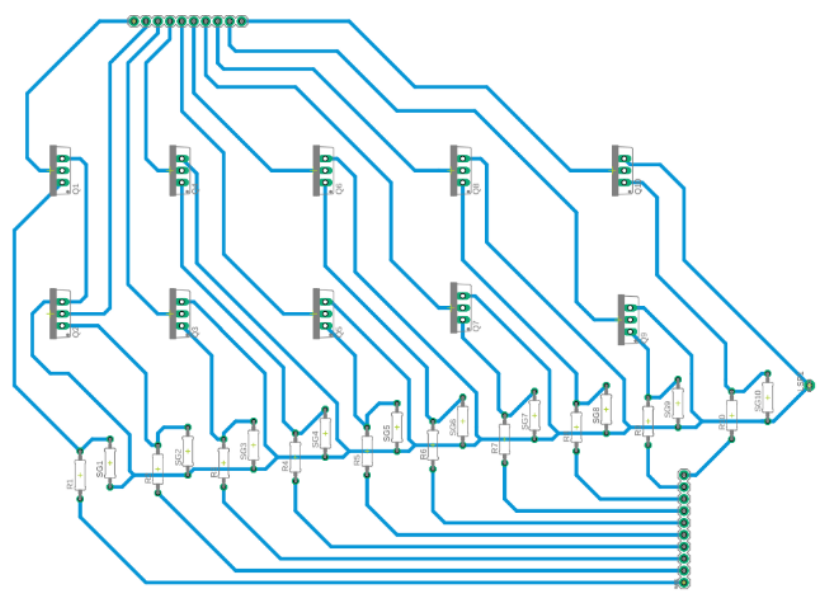

Gambar 14. Desain PCB untuk MOSFET

\section{E. Perancangan Sistem Display LCD}

Untuk perancangan alat ini, digunakan display LCD 20x4. Untuk instalasinya, LCD menggunakan modul tambahan yaitu I2C sebagai komunikasi data antara arduino dan LCD, selain itu, dengan menggunakan I2C, rangkaian lebih sederhana karena penggunaan pin yang lebih sedikit. Berikut skematik rangkaian komponen ditunjukkan pada Gambar 15. LCD pada sistem akan menampilkan menu yang terdiri dari beberapa opsi untuk mengatur LED dengan bervariasi, untuk mengatur atau memilih navigasi menu, digunakan komponen rotary encoder, LCD juga menampilkan duty cycle sebagai indikator batas minimal dan maksimal sinyal PWM yang dikirimkan ke LED driver.

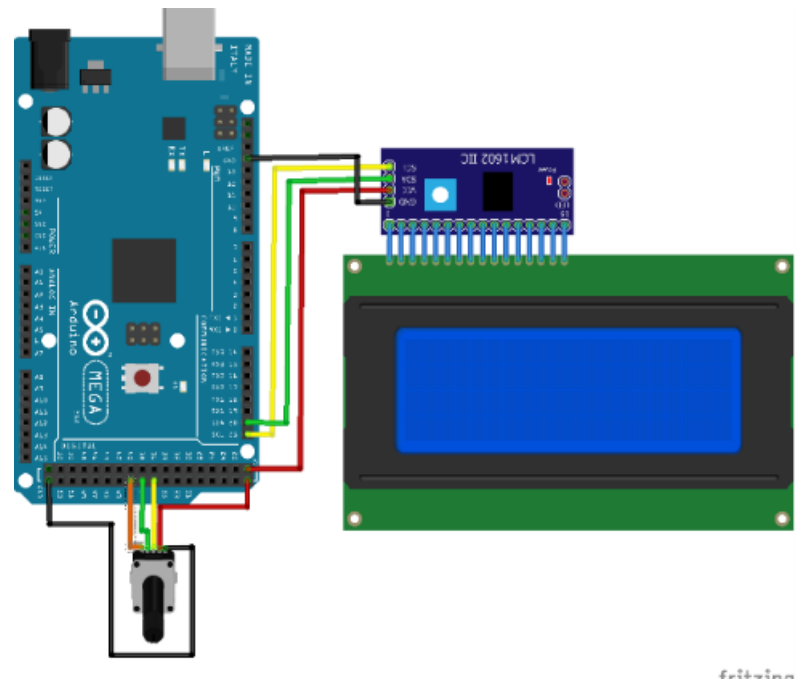

Gambar 15. Skematik rangkaian LCD pada Arduino

\section{F. Perancangan Sistem Catu Daya}

Catu daya yang digunakan pada sistem yaitu jenis SMPS sebagai catu daya utama yang merubah listrik dari PLN 220 VAC menjadi 12 VDC untuk didistribusikan pada sistem, untuk menentukan catu daya tersebut, maka dilakukan perhitungan untuk menentukan maksimal daya yang akan digunakan. high power LED yang pada dasarnya yang memiliki spesifikasi arus forward yang besar, maka untuk perhitungan arus total sebagai berikut, IF $=350 \mathrm{~mA}$, maka arus total $=$ arus yang meninggalkan percabangan, terdapat 2 LED seri yang dirangkai secara paralel, total terdapat 20 percabangan dengan asumsi bahwa setiap cabang akan dialiri $350 \mathrm{~mA}$, sehingga:

$$
\begin{aligned}
I_{\text {total }} & =I F_{\text {seri }} \times L E D \text { paralel } \\
& =0.350 \mathrm{~A} \times 20 \\
& =7 \mathrm{~A} \\
P=V & \times I_{\text {total }} \\
& =12 \times 7 \\
& =84 \mathrm{Watt}
\end{aligned}
$$

Di mana:

$$
\begin{array}{ll}
I_{\text {total }} & =\text { Arus total pada sistem } \\
I F_{\text {seri }} & =\text { arus pada rangkaian seri } L E D \\
L E D_{\text {paralel }}= & \text { adalah jumlah percabangan pada susunan } \\
& \text { LED } \\
P & =\text { daya } \\
V & =\text { tegangan sumber }
\end{array}
$$

Perhitungan $\mathrm{I}_{\text {total }}$ digunakan untuk menghitung nilai arus untuk mengaktifkan sistem LED sebanyak 40 buah berdasarkan rangkaian yang telah dibuat. Dengan dasar perhitungan 3. 2 dan perhitungan 3.3, maka dapat ditentukan spesifikasi rating SMPS yang digunakan untuk sistem adalah $12 \mathrm{~V}$ dan arus $10 \mathrm{~A}$, sesuai yang ada di pasaran. 


\section{G. Perancangan Capasitor Bank}

Pada sistem, capasitor bank ini digunakan sebagai pengaman dari kapasitor yang terdapat pada catu daya dan mengurangi tegangan jatuh saat sistem dalam keadaaan berbeban. Berikut perancangan PCB ditunjukkan pada Gambar 16. Terdiri dari terminal block input dan output, tiga buah kapasitor 1000 mikrofarad dan fuse holder.

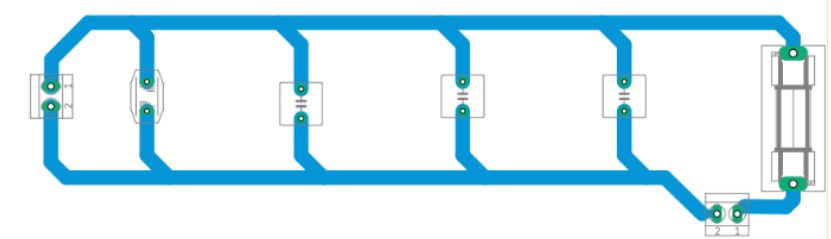

Gambar 16. Desain PCB untuk rangkaian capasitor bank

\section{H. Perancangan Output Fotovoltaik}

Untuk panel surya dengan jenis polycrystalline dengan dimensi panjang $=38 \mathrm{~cm}$, lebar $=26 \mathrm{~cm}$ dan tebal $=2,5 \mathrm{~cm}$, mampu membangkitkan daya listrik $10 \mathrm{WP}$, dengan tegangan rangkaian terbuka (Voc) $=22 \mathrm{~V}$, arus hubung singkat (Isc) $=0.58 \mathrm{~A}$, dan jumlah sel adalah 36 . Pada beban panel surya menggunakan dua buah lampu high power LED model 2B5C: daya 5 Watt, dengan tegangan forward $15-$ $16 \mathrm{~V}$ dan arus forward 240 - $260 \mathrm{~mA}$ yang dirangkai secara paralel.

\section{Diagram Alir}

Pada sistem pemrograman Arduino terdapat alur-alur dimana program dieksekusi, berikut penjabaran setiap proses program ditunjukkan dalam bentuk diagram alir. Pada Gambar 17 merupakan diagram alir untuk program utama di mana setiap fungsi menjalankan sub-sub fungsi lainnya, pada awal proses mikrokontroler akan membaca deklarasi library, variable, konfigurasi pin dan fungsi. Sistemnya akan diproses bertahap pada urutan barisnya.

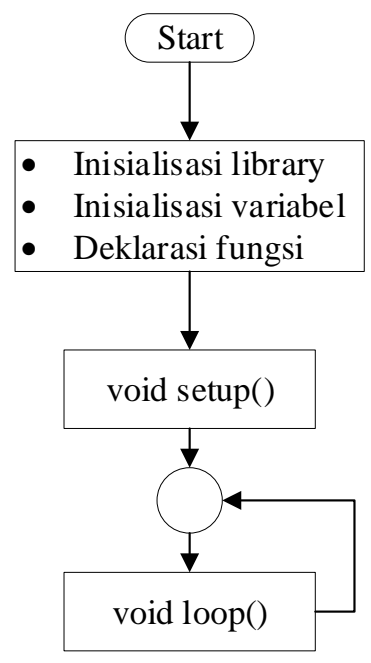

Gambar 17. Diagram alir program Arduino

Pada void setup() setiap program pada fungsi ini akan dieksekusi sekali setiap program dijalankan, fungsi ini merupakan fungsi utama pada pemrograman arduino. Umumnya digunakan untuk inisiasi input dan output. Untuk penjabaran proses pada fungsi void $\operatorname{setup}()$ di sistem modul ini sebagai berikut ditunjukkan pada Gambar 18.

Gambar 19 menunjukkan tentang diagram alir prosesproses yang terdapat pada void loop(), dimana setiap program yang terdapat pada fungsi ini akan dioperasikan terus menerus secara berulang. Terdapat beberapa fungsi-fungsi di dalam loop() yang memiliki tugas masing-masing.

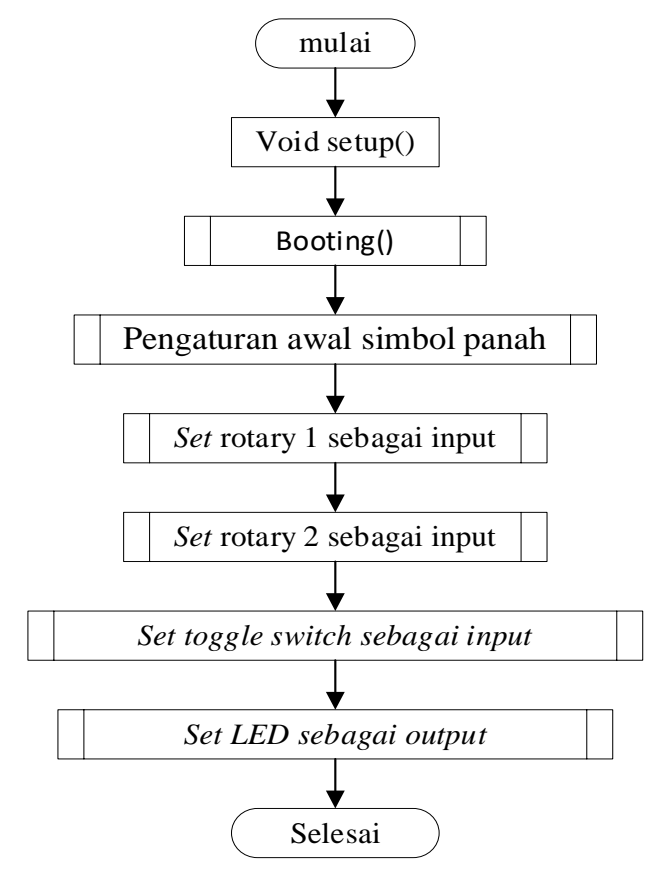

Gambar 18. Diagram alir fungsi setup()

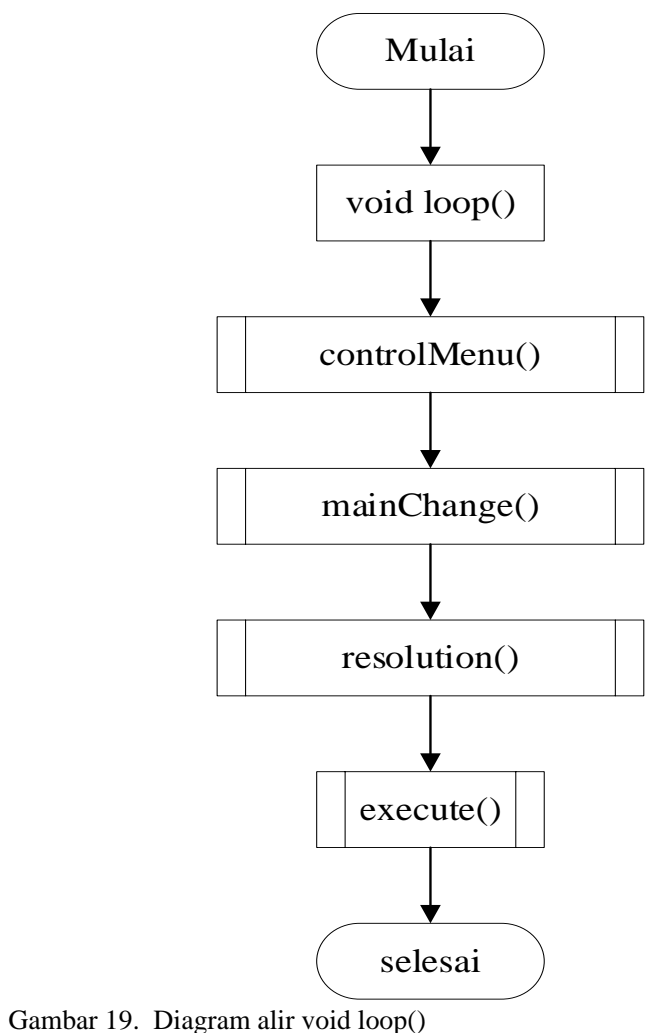




\section{IV.HASIL DAN PEMBAHASAN}

\section{A. Proses Pembuatan Alat}

Tahapan ini merupakan proses dimana komponen dan material dieksekusi, merakit dan membangun sistem menjadi satu kesatuan berdasarkan perencanaan yang sudah dibuat, namun tidak semua perencanaan yang dibuat akan berjalan lancar saat pengerjaan, sehingga selalu ada tindakan untuk hal-hal yang sifatnya tidak terencana ketika pengerjaan alat ini. Setiap proses pengerjaan akan menggunakan peralatan dan komponen yang berbeda. Beberapa tahapan pengerjaan alat ini adalah sebagai berikut.

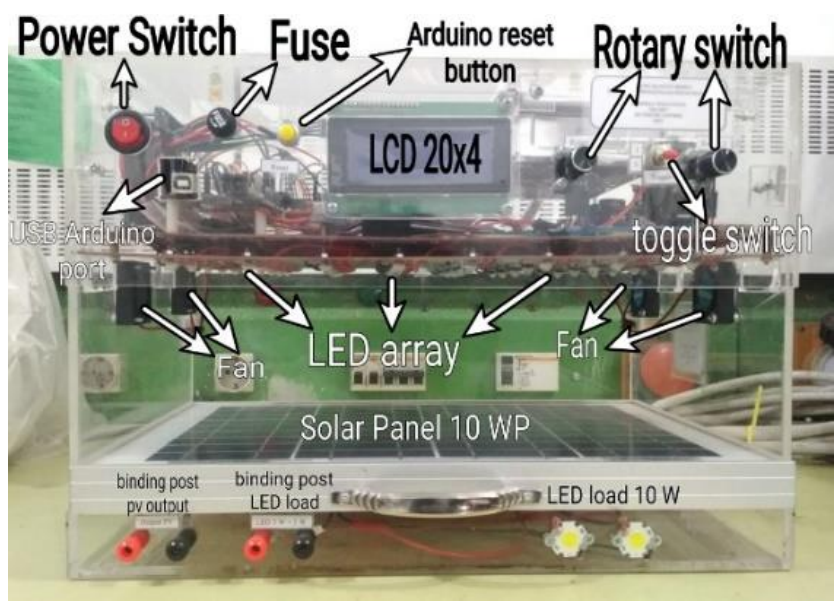

Gambar 20. Komponen-komponen pada modul

Berikut proses perakitan komponen dengan melewati beberapa proses sebagai berikut:

\section{1). Perakitan Wadah}

Material yang digunakan untuk pembuatan wadah ini adalah material akrilik dengan tebal $5 \mathrm{~mm}$ dan untuk dimensi bentuk berdasarkan desain perencanaan, lembaran akrilik yang telah dipotong sesuai ukuran, selanjutnya disatukan membentuk kotak menggunakan siku. saat posisi telah sesuai, sisi yang terhubung direkatkan menggunakan lem khusus akrilik. Kemudian bagian-bagian yang perlu dilubangi untuk tempat komponen seperti LCD, rotary encoder, sakelar toggle, sakelar power, tombol reset Arduino, tempat fuse dan enam buah kipas.

\section{2). Perakitan LED}

Untuk material yang digunakan adalah PCB dengan dimensi $24 \mathrm{~cm}$ x $38 \mathrm{~cm}$, lampu LED $1 \mathrm{~W}$ dengan heatsink aluminium sebanyak 40 buah, baut dan mur $3 \mathrm{~mm}$ sebanyak 80 buah dan kabel JST. Pemasangan LED ditunjukkan pada Gambar 21.

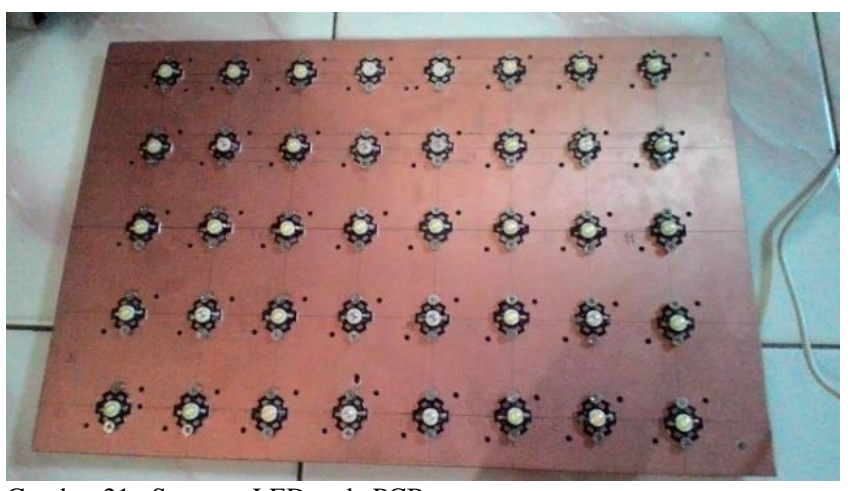

Gambar 21. Susunan LED pada PCB

\section{3). Pembuatan rangkaian $\mathrm{PCB}$}

Untuk pembuatan rangkaian $\mathrm{PCB}$, tahapannya terdiri dari mendesain rangkaian, mencetak desain ke $\mathrm{PCB}$, proses pelarutan tembaga, kemudian pemasangan komponen pada PCB dengan timah solder. Berikut salah satu PCB yang digunakan saat proses pencetakan.

\section{4). Perakitan seluruh Bagian}

Pada proses terakhir seluruh bagian dirakit menjadi satu, dengan peletakan komponen pada wadah penyesuaian lokasi komponen, kemudian pengkabelan antar bagian hingga menjadi suatu sistem, kemudian juga pemasangan label nama dan label untuk lokasi komponen pada tampilan muka alat.

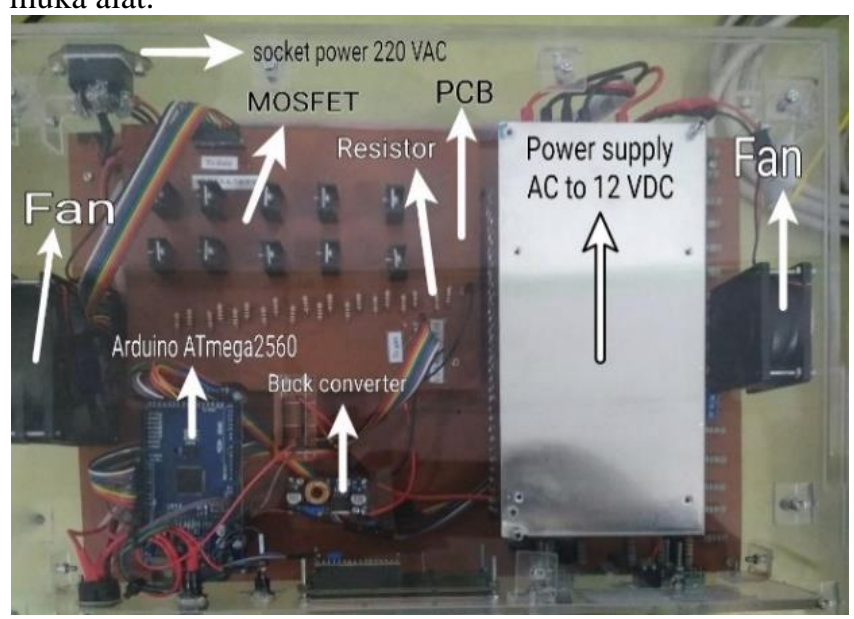

Gambar 22. Komponen-komponen pada modul tampak atas

\section{5). Pengujian Catu Daya}

Pada pengujian awal dilakukan pengukuran daya listrik PLN, dengan tegangan terukur adalah 231.6 VAC. Kemudian pengujian dilakukan untuk mengukur arus, tegangan dan daya untuk input AC sistem. Pengujian dilakukan dengan mengambil beberapa pengukuran untuk setiap pengaturan LED yang berbeda, data pengukuran ditunjukkan pada Tabel $\underline{2}$. 
TABEL 2

DATA PENGUKURAN UNTUK PEMAKAIAN DAYA

\begin{tabular}{|l|l|l|l|l|}
\hline \multicolumn{2}{|c|}{ Stand by } & V $(\mathrm{V})$ & $\mathrm{I}(\mathrm{A})$ & $\mathrm{P}(\mathrm{W})$ \\
\hline \multirow{4}{*}{ Berbeban } & 231.9 & 0.131 & 17 \\
\cline { 2 - 5 } & Hijau & 232.4 & 0.216 & 29.3 \\
\cline { 2 - 5 } & Biru & 233.6 & 0.188 & 25.3 \\
\cline { 2 - 5 } & Putih hangat & 233.7 & 0.203 & 27 \\
\cline { 2 - 5 } & Merah & 234.2 & 0.238 & 32.3 \\
\cline { 2 - 5 } & Putih & 234 & 0.201 & 27.1 \\
\cline { 2 - 5 } & Putih 24 buah & 233.2 & 0.577 & 83 \\
\cline { 2 - 5 } & Semua LED & 234 & 0.852 & 123.2 \\
\hline
\end{tabular}

Sistem dari modul ini menggunakan catu daya SMPS untuk merubah daya AC PLN menjadi DC agar dapat digunakan pada sistem, SMPS yang digunakan memiliki rating $12 \mathrm{~V}$ dan arus $10 \mathrm{~A}$. Pada pengujian catu daya SMPS didapat tegangan keluaran $12.96 \mathrm{~V}$ dalam keadaan tidak berbeban, kemudian setelah diberi beban maksimal dengan mengaktifkan seluruh LED nilai tegangan menjadi jatuh pada 12.31 V. Pada pengukuran arus total sistem, didapatkan nilai pengukuran arus ketika seluruh beban aktif adalah 6.88 A.

Buck converter pada sistem ini digunakan sebagai catu daya untuk Arduino, dengan sumber tegangan yang disarankan untuk Arduino berkisar pada 7-12 VDC. Pada pengujian ini tegangan pada buck converter output yang terukur adalah $10.17 \mathrm{~V}$.

\section{6). Pengujian MOSFET}

Pada pengujian ini pegaturan duty cycle PWM diatur maksimum 100\%. Dilakukan pengukuran beberapa parameter yaitu, pengukuran pada tegangan gate-source $\left(\mathrm{V}_{\mathrm{GS}}\right)$ saat MOSFET aktif dan arus drain seperti yang ditunjukkan pada Tabel 3.

TABEL 3

PENGUJIAN PADA MOSFET

\begin{tabular}{|c|c|c|c|c|}
\hline No & Kode & $\mathbf{V}_{\mathbf{G S}}(\mathbf{V})$ & $\mathbf{I}_{\mathbf{D}}(\mathbf{A})$ & $\begin{array}{c}\text { Duty Cycle } \\
(\boldsymbol{\%})\end{array}$ \\
\hline 1 & White1 & 4.68 & 0.7 & 100 \\
\hline 2 & White2 & 4.68 & 0.666 & 100 \\
\hline 3 & White3 & 4.68 & 0.643 & 100 \\
\hline 4 & White4 & 4.68 & 0.616 & 100 \\
\hline 5 & White5 & 4.68 & 0.615 & 100 \\
\hline 6 & Green & 4.68 & 0.740 & 100 \\
\hline 7 & Blue & 4.68 & 0.623 & 100 \\
\hline 8 & Warm & 4.68 & 0.63 & 100 \\
\hline 9 & Red & 4.68 & 0.8 & 100 \\
\hline 10 & White6 & 4.68 & 0.65 & 100 \\
\hline
\end{tabular}

7). Pengujian Arduino

Pada Arduino dilakukan pengetesan unjuk kerja, Arduino diberi suplai daya yang dengan tegangan 10,24 VDC dari buck converter, kemudian dilakukan pengukuran output tegangan dari Arduino pada pin $5 \mathrm{~V}$ tegangan terukur adalah 4,89 V, kemudian untuk tegangan pada pin PWM yang digunakan untuk pengaktifan MOSFET ditunjukkan pada Tabel 4.
TABEL 4. PENGUKURAN TEGANGAN PADA PIN PWM

\begin{tabular}{|c|c|c|}
\hline No & No Pin & Tegangan PWM (V) \\
\hline $\mathbf{1}$ & $\mathbf{2}$ & 4.901 \\
\hline $\mathbf{2}$ & $\mathbf{3}$ & 4.897 \\
\hline $\mathbf{3}$ & $\mathbf{4}$ & 4.910 \\
\hline $\mathbf{4}$ & $\mathbf{5}$ & 4.912 \\
\hline $\mathbf{5}$ & $\mathbf{6}$ & 4.912 \\
\hline $\mathbf{6}$ & $\mathbf{7}$ & 4.910 \\
\hline $\mathbf{7}$ & $\mathbf{8}$ & 4.921 \\
\hline $\mathbf{8}$ & $\mathbf{9}$ & 4.910 \\
\hline $\mathbf{9}$ & $\mathbf{1 0}$ & 4.911 \\
\hline $\mathbf{1 0}$ & $\mathbf{1 1}$ & 4.904 \\
\hline
\end{tabular}

\section{8). Pengujian LCD}

LCD yang telah terhubung pada sistem rangkaian dicoba untuk menampilkan karakter-karakter yang telah diprogram pada Arduino, LCD bekerja secara normal, kemudian untuk menyesuaikan kecerahan dari tampilan LCD dengan mengatur trimmer potensiometer yang terdapat di belakang LCD.

\section{9). Pengujian Panel Surya}

Pada pengujian ini dilakukan dengan memberikan penyinaran langsung oleh matahari terhadap panel surya, dilakukan pada 29 Juni 2019 pukul 14.05 WITA, di depan Laboratorium Teknik Elektro. Data pengujian sebagai berikut pada Tabel 5 .

TABEL 5

DATA PENGUJIAN PANEL SURYA TERHADAP MATAHARI

\begin{tabular}{|c|c|c|c|c|}
\hline No & $\begin{array}{c}\text { Waktu } \\
(\text { menit })\end{array}$ & $\begin{array}{c}\text { Tegangan: Voc } \\
(\mathrm{V})\end{array}$ & $\begin{array}{c}\text { Arus: Isc } \\
(\mathrm{A})\end{array}$ & $\begin{array}{c}\text { Intensitas cahaya } \\
(\text { lux })\end{array}$ \\
\hline 1 & 0 & 20.3 & 0.54 & 103300 \\
\hline 2 & 15 & 18.1 & 0.11 & 25000 \\
\hline 3 & 30 & 17.5 & 0.11 & 22800 \\
\hline 4 & 45 & 19.2 & 0.28 & 43100 \\
\hline 5 & 60 & 18.39 & 0.069 & 13600 \\
\hline 6 & 75 & 18.52 & 0.067 & 13500 \\
\hline
\end{tabular}

10). Pengujian Kerja Sistem

Pada pengujian sistem, dilakukan serangkaian percobaan pada kondisi normal operasi dengan melakukan beberapa pengukuran yaitu:

\section{a. Pengukuran Intensitas Cahaya}

Pengujian ini dilakukan untuk menguji intensitas cahaya yang dihasilkan dari modul simulator surya terhadap area yang disinari langsung oleh lampu LED. Maka dari itu digunakan alat ukur lux meter pada percobaan ini dengan pengambilan data dibeberapa titik penyinaran untuk setiap pengujiannya. Berikut data dari pengukuran tersebut ditunjukkan dalam skema pada Gambar 23 berdasarkan area penyinarannya. 


\begin{tabular}{|c|c|c|}
\hline Belakang kiri & Belakang tengah & Belakang kanan \\
\hline 12620 & 14600 & 13630 \\
lux & lux & lux \\
\hline Depan Kiri & Depan tengah & Depan kanan \\
\hline 12760 & 14650 & 12140 \\
lux & lux & lux \\
\hline mbar 23. Intensitas cahaya maksimal modul untuk semua LED
\end{tabular}

Gambar 23. Intensitas cahaya maksimal modul untuk semua LED

\section{b. Pengujian Fotovoltaik pada Simulator Surya}

Pada pengujian ini simulator surya digunakan untuk menyinari panel surya. Pengujian dilakukan dua tahap yaitu tidak berbeban dengan parameter (Voc dan Isc) dan mengukur arus dan tegangan saat berbeban yang menggunakan dua buah LED masing-masing $5 \mathrm{~W}$.

TABEL 6

DATA PENGUKURAN KELUARAN FOTOVOLTAIK

\begin{tabular}{|c|c|c|c|}
\hline \multicolumn{4}{|c|}{ Tidak Berbeban } \\
\hline Warna LED & Duty Cycle (\%) & Voc (V) & Isc (mA) \\
\hline Semua LED & 20 & 11 & 10.22 \\
\cline { 2 - 4 } & 40 & 13.62 & 19 \\
\cline { 2 - 4 } & 60 & 16.02 & 27.02 \\
\cline { 2 - 4 } & 80 & 17.33 & 35.17 \\
\cline { 2 - 4 } & 100 & 18.32 & 42.07 \\
\hline \multirow{4}{*}{ Semua LED } & 20 & 9.63 & 8.09 \\
\cline { 2 - 4 } & 40 & 11.16 & 14.3 \\
\cline { 2 - 4 } & 60 & 12.8 & 22.4 \\
\cline { 2 - 4 } & 80 & 13.39 & 30.29 \\
\cline { 2 - 4 } & 100 & 13.58 & 36.46 \\
\hline
\end{tabular}

\section{1). Pengujian Suhu Kerja Sistem}

Pada pengujian ini dilakukan pengoperasian dalam jangka waktu 30 menit, kemudian mengukur suhu menggunakan thermo gun pada beberapa bagian komponen, meliputi catu daya SMPS, MOSFET, kapasitor, Arduino, buck converter dan susunan LED dengan suhu rata-rata mencapai $30-40^{\circ} \mathrm{C}$. Sedangkan suhu terpanas terdapat pada pengukuran resistor LED dengan suhu di beberapa resistor yang mencapai $75^{\circ} \mathrm{C}$ keatas.

\section{2). Pembuatan Job Sheet Praktikum Laboratorium}

Untuk pembuatan job sheet, acuan format yang digunakan berdasarkan modul praktikum yang telah digunakan pada Laboratorium Elektronika Daya, dengan bagian-bagian pada modul tersebut yaitu terdiri dari 1) Perlengkapan dan alat yang digunakan; 2) Tujuan; 3) Prosedur Praktik; 4) Parameter operasi; 5) Gambar rangkaian percobaan; 6) Data percobaan; 7) Analisa data; dan 8) Kesimpulan.

\section{KESIMPULAN}

Setelah melaksanakan perancangan dan pembangunan modul praktikum untuk penggunaan fotovoltaik dengan serangkaian kegiatan mulai dari mempelajari literasi yang berkaitan dengan fotovoltaik dan simulator surya, memilih komponen-komponen utama yang dibutuhkan, kemudian ke tahap perancangan, hingga pada pembangunan rancangan menjadi suatu modul dapat diambil kesimpulan sebagai berikut:

1). Berdasarkan hasil pengujian pada penyinaran setiap warna LED terhadap panel surya, diketahui bahwa setiap spektrum warna memiliki jumlah energi poton yang berbeda. Sehingga, walaupun intensitas penyinaran sama, daya yang dihasilkan pada fotovoltaik belum tentu sama. Hal tersebut terbukti pada penyinaran dengan LED merah yang menghasilkan lebih besar daya dibandingkan hijau, biru atau warm. Kemudian putih dengan daya yang dihasilkan lebih tinggi karena merupakan warna yang dihasilkan dari seluruh spektrum warna terlihat.

2). Berdasarkan pengukuran suhu operasi sistem pada beban penuh, resistor LED dapat mencapai suhu diatas $75^{\circ} \mathrm{C}$ dan untuk pengujian operasi terlama mencapai 40 menit.

3). Karena spektrum LED yang digunakan adalah spektrum dengan rentang gelombang $400-800 \mathrm{~nm}$ (cahaya terlihat oleh mata manusia) berdasarkan datasheet LED dan intensitas cahaya yang belum menyamai matahari. Sehingga untuk spektrum dan juga intensitas cahaya yang dihasilkan oleh modul simulator surya ini belum mendekati dengan standar kelas simulator surya komersial yang berlaku ataupun mendekati sinar matahari, tetapi dengan hasil pengujian keluaran PV mencapai tegangan open circuit $=18,5 \mathrm{~V}$ dan arus short circuit $=42 \mathrm{~mA}$ dapat membuktikan bahwa modul ini dapat digunakan sebagai alat untuk mensimulasikan matahari untuk tujuan edukasi.

\section{REFERENSI}

[1] R. Foster, M. Ghassemi dan A. Cota, Solar Energy And Renewable Energy Environment, United State of America: CRC Press Taylor \& Francis Group, 2010.

[2] M. Masters, Renewable and Efficient Electric Power System, $2^{\text {nd }}$ edition, United State of America: John Wiley \& Sons, Inc., 2013.

[3] P. Hersch dan K. Zweibel, Basic Photovoltaic Principles and Methodes, U.S. Government Printing Office, Washington DC, 1982

[4] Anjarani, S. Sidopekso, "Studi karakteristik arus - tegangan (I V) pada sel tunggal polikristal silikon dan pemodelannya”, Prosiding Pertemuan Ilmiah XXV HFI Jateng \& DIY,

[5] W. Wang, Simulate a 'Sun' for Solar Research: A Literature Review of Solar Simulator Technology, Department of Energy Technology, Stockholm, 2014.

[6] OMS Lighting, Ltd., LED Academy, Available :http://www.omslighting.com/data/images/ledacademy/pdf/led_ academy.pdf

[7] E. Strandberg dan J. Robbins, The Basic of LEDs, Lighting Design Lab, 2012.

[8] https://docplayer.info/30348975-Pengenalan-arduino-juli-2011tingkat-oleh-feri-djuandi-pemula-menengah-mahir.html.

[9] Arduino, Arduino Mega 2560, datasheet.

[10] Lighthouse LEDs, 1 Watt LED star, datasheet. 